Fecha de recepción: abril 2020 Fecha de aceptación: mayo 2020 Versión final: junio 2020

\section{La Bauhaus en el origen de los principios pedagógicos para una proyectualidad poética.}

Jorge Pokropek ${ }^{(1)}$

Resumen: La influencia de la Bauhaus en los modos actuales de instrumentar lógicas pedagógicas orientadas a la formación de arquitectos y diseñadores ha sido enorme. Tanto sus innegables aportes en la construcción de saberes como en la configuración de criterios y métodos fue tan profunda que se ha "naturalizado", olvidándose a veces el origen y contexto que la determinaron. Interesa aquí evaluar, como profesores en las áreas proyectuales, cuáles son aún los saberes, criterios y métodos vigentes y aplicables a la instrumentación de eficaces lógicas pedagógicas para una proyectualidad poética. Interesa también advertir como los procedimientos y teorías desarrolladas por la Bauhaus constituyen el origen mismo de las actuales disciplinas Morfología y Heurística.

Palabras clave: Bauhaus - diseño - morfología - heurística - poética.

[Resúmenes en inglés y portugués en las páginas 55-56]

(1) Magister en Lógica y Técnica de la forma, FADU-UBA. Especialista en Lógica y Técnica de la forma, FADU-UBA. Arquitecto, Universidad de Morón. Cursó la carrera de posgrado de Planificación Urbana y Territorial e Investigación en Pueblos en Vías de Desarrollo, UM. Cursó la Maestría en Diseño Arquitectónico y Urbano, FADU-UBA. Realizó múltiples talleres de Investigación proyectual, Centro Poiesis, SCA, FADU-UBA. Profesor en Diseño y Adjunto en Arquitectura 3, UM. Profesor en Morfología, FADU-UBA, Profesor titular en la carrera de Especialización en Lógica y Técnica de la forma, FADU-UBA. Autor de numerosas publicaciones sobre arquitectura y ciudad. Titular del estudio de arquitectura Pokropek y asociados.

\title{
Comentarios preliminares
}

En 2019 se han cumplido cien años desde la fundación de la Bauhaus, aquella ya mítica "escuela de diseño" que influyó de un modo tan profundo y extenso en la configuración de nuestros actuales enfoques sobre los objetivos y mecanismos pedagógicos que instrumentan las prácticas de enseñanza y aprendizaje en la prefiguración proyectual y producción de formas estéticamente intencionadas. 
A raíz del reconocimiento global sobre la protagónica presencia de la Bauhaus en la historia de la pedagogía proyectual que determinó la consecuente producción de formas constituyentes del entorno actual es que creemos oportuno y necesario revisar las razones por las cuales hoy todavía esa presencia protagónica se manifiesta de maneras explicitas o tacitas, tanto en nuestra praxis proyectual profesional como en los modos, temas y problemas que guían la enseñanza del proyecto.

Advirtamos que esta revisión crítica tendrá como plataforma nuestros saberes y actividades como profesores de proyecto, desde las específicas áreas de la morfología arquitectónica y objetual. No somos historiadores sino diseñadores que reflexionan sobre los modos mejores de producir formas para configurar un entorno habitable más rico, tendiente a estimular una existencia humana poéticamente plena, llena de belleza y sentido.

Este esfuerzo se dirige, entonces, a contribuir en la construcción de una "Teoría del Proyecto" vinculada a una "Teoría de la Arquitectura" participando así en el paisaje conceptual de nuestra Tesis Doctoral, focalizada precisamente en la configuración de lógicas proyectuales poéticamente intencionadas, factibles de emplearse para mejorar la calidad de toda producción formal.

Recordemos al respecto, que la hipótesis fundamental de dicha tesis doctoral dice así:

Las lógicas proyectuales que incrementan la dimensión poética de la forma arquitectónica son aquellas que incrementan su ambigüedad y autorreferencialidad mediante un proceso de metaforización formal sostenido por operaciones retóricas que determinan estructuras rítmicas.

La cita merece algunas aclaraciones inmediatas. Observemos que se pretende "incrementar la dimensión poética de la forma arquitectónica", entendiendo que la "forma arquitectónica" es la protagonista de nuestras preocupaciones.

Señalemos, sin embargo, que como ya hemos explicitado en otros textos toda estrategia proyectual general tendiente a incrementar la calidad o valor de la "forma arquitectónica" puede aplicarse exitosamente a la prefiguración y producción del resto de las formas objetuales (artesanales, industriales, indumentales, graficas, etc.). Observemos, asimismo, que el actual deslinde entre formas arquitectónicas y objetuales, sostenido por el consecuente deslinde de la enseñanza en carreras específicas, no tenía en la Bauhaus excesiva importancia. Digamos también, en aras de una mayor claridad conceptual, que para Umberto Eco (1986) la arquitectura era "todo aquel producto artificial que constituye el entorno humano", desde las catedrales hasta los pantalones. Eco desarrolló su investigación semiótica sobre la generalidad de las formas-función, proponiendo que las lógicas configurativas del mensaje estético pueden aplicarse sin ninguna discriminación a todo el universo formal de producción humana. Este universo formal artificial estéticamente intencionado en su prefiguración-producción constituía el territorio de las "artes aplicadas", foco de los esfuerzos pedagógicos de los "profesores-artistas" nucleados en la Bauhaus.

Otra aclaración inmediata por necesaria es nuestra noción de "dimensión poética arquitectónica".

Señalemos entonces que por "dimensión poética arquitectónica" entendemos la capacidad de la forma arquitectónica para reinterpretar, renovar y transformar la realidad incremen- 
tándola o enriqueciéndola mediante un "acto poético" orientado hacia la renovación de los mitos subyacentes en los programas simbólico-operativos determinados por las humanas prácticas sociales. La "dimensión poética” mide entonces el valor estético de la forma arquitectónica y su capacidad para renovar al mundo. En un sentido parecido conviene advertir aquí que la noción de "poética" se aplica desde la perspectiva de Roman Jakobson (1975), es decir, como el estudio de los modos en que las organizaciones de signos producen un efecto estético, trascendiendo la función prosaica o informativa del lenguaje y convirtiéndose en "objeto artístico".

Este es el enfoque que nos permite recordarlo tantas veces expresado:"Poetizar, hacer poética, es construir una forma ambigua y autorreflexiva, orientada al estímulo de experiencia estética mediante operaciones retoricas sobre un lenguaje" (Pokropek-Cravino, 2019).

Recordemos también que los diseñadores debemos satisfacer el mandato ético de "poetizar al mundo" mediante la producción de formas estéticamente intensas, ya que, en principio, todo incremento en la dimensión poética artefactual estimulara un incremento en la dimensión poética humana. "Poéticamente habita el hombre" decía Heidegger (1994) siguiendo a Hölderlin.

Advirtamos ahora que nuestra insistencia en emplear la noción de "poética" para cumplir con el mandato ético-estético de poetizar las formas para poetizar al mundo y lograr así sensibles mejoras de la condición humana, tiene, además como objetivo ideológico traducido en estrategias pedagógicas, buscar desocultar y transformar otras estrategias pedagógicas que por ignorancia o indolencia descuidan el diseño consciente y potente del aspecto estético-poético que las formas deben expresar, asumiendo que el mismo puede ser la consecuencia casual o lateral, aunque deseable, de un aparente saber-hacer focalizado en satisfacer protagónicamente necesidades prosaicas o utilitarias, ingenuamente llamadas "funcionales", sin pretender transcenderlas intencionadamente por concebir como "frívola" o "innecesaria" la posibilidad de "belleza".

En otros textos hemos profundizado en los históricos vaivenes de la noción de belleza y su presencia, necesaria o no, en el arte y el diseño. Insistamos simplemente en reseñar que ya desde hace un tiempo esta noción ha sido revalorizada como un valor humano eficaz para hacer un mundo mejor.

Observemos, por cierto, que la condición necesaria para que una forma sea considerada estadísticamente "bella" por la mayoría de los seres humanos socializados tiene que ver con el grado o intensidad de sus niveles de coherencia interna que determinan, entre otras cosas, su posibilidad de llamar la atención sobre las lógicas de su expresión. Esta condición de autorreferencialidad formal inherente a la anatomía propia de todo mensaje estético debiera ser el foco de nuestros procesos proyectuales, ya que las funciones prosaicas tienden a satisfacerse fácilmente; no así las funciones poéticas.

Todas estas aclaraciones sobre nuestros enfoques y modos de expresión literaria confluyen en el deseo de poder explicitar con rigor epistemológico las coincidencias y divergencias que hoy tenemos con la "pedagogía Bauhaus", evaluando las enormes deudas contraídas por sus aportes innegables, pero también revelando los prejuicios o malentendidos que esta "escuela" nos hizo internalizar o naturalizar como falsas verdades axiomáticas esclerosando saberes que obturaron a veces la construcción de conocimientos nuevos. 
Interesa entonces aquí, fundamentalmente, volver a revisar esos saberes aportados por la Bauhaus y ya tan naturalizados que pocos recuerdan su origen y condición provisoria. Pretendemos demostrar como la Bauhaus está en el origen mismo de nuestra actual proyectualidad poética.

\section{Algunos comentarios sobre la pedagogía de la Bauhaus}

La pedagogía de la Bauhaus es el título de un texto profundo y extenso de Rainer Wick (1993) escrito en 1982. Desde su publicación constituye una de las fuentes fundamentales para indagar en los sucesivos enfoques, objetivos y mecanismos pedagógicos que los diversos "profesores-artistas" aportaron al debate sobre los criterios para estimular el aprendizaje de la prefiguración y producción de aquellas formas que, constituyentes del entorno habitable, debían reunir en si las virtudes del arte y la ciencia, constituyéndose en una síntesis nueva donde las capacidades de las máquinas de la revolución industrial no podían ser éticamente desaprovechadas aun cuando se considerase prioritaria la comunión entre arte y artesanía.

Esta confusión aparente de objetivos que pretendían simultáneamente responder a las necesidades propias del arte, la artesanía y la industria causaron y siguen causando diversos conflictos a la hora de decidir planes de estudio, contenidos curriculares, o estrategias pedagógicas.

Todavía hoy hay profesores de las áreas proyectuales que tienden a negar la posible condición artística de los objetos arquitectónicos y objetuales, por entender erróneamente que los procesos proyectuales configurados por sucesivos actos de "diseño" se apartan de los métodos tradicionales configurativos del llamado "arte puro" y, por ende, los productos del "diseño", al no pertenecer al universo artístico, no necesitan prioritariamente estimular una experiencia estética en sus usuarios o "fruidores".

Contra este equivoco ya hemos luchado extensamente en otros textos. Aquí nos limitaremos a enfatizar que el heterogéneo cuerpo docente que en verdad constituía la esquiva noción de una "pedagogía Bauhaus", resultante de la confluencia de personalidades intensas y diversas, se homogeneizaba bajo el concepto común de "profesores-artistas".

La condición de "artista” era ineludible para poder estimular aprendizajes en la Bauhaus. Y decimos "estimular aprendizajes" pues había consenso parcial, en esos momentos, en que el "arte" no podía “enseñarse" pero si "aprenderse”. Desde Gropius hasta Albers, pasando por Itten, Moholy-Nagy, Kandinsky, Klee, Schlemmer, Joost Schmidt y Mies van der Rohe, existía la convicción de que solo se podía "enseñar" algunos conceptos y mecanismos tendientes a la configuración de lógicas de prefiguración y producción formal orientadas a satisfacer tanto objetivos estéticos como funcionales.

$\mathrm{Al}$ incorporar estas lógicas de prefiguración-producción el estudiante obtenía un saber hacer poético que no garantizaba su condición de "artista", pero si la de maestro en la producción de formas. Lo que hoy llamaríamos un "diseñador".

Advirtamos que, en nuestros "comentarios preliminares" definimos inicialmente a la Bauhaus como una mítica "escuela de diseño". Observemos ya que, en ese momento histórico, 
las nociones de "diseño" y de "diseñador" no existían como las conceptualizamos hoy. De hecho uno de los grandes méritos de la Bauhaus ha sido precisamente ayudar a definir y recortar un territorio de la actividad humana productora de sentido mediante la prefiguración y producción de formas que tienen como nociones protagónicas al proyecto y al diseño. Conviene aquí, brevemente, estipular nuestro uso de estos términos y el modo en que se relacionan. Entendemos por proyecto poético al resultado de un proceso de diseño o proceso proyectual tendiente a prefigurar una forma mediante un modelo hipotéticoiterativo (Doberti, 2006) que secuencia proposiciones buscando incrementar la coherencia interna de dicha forma a fin de revelar su aspecto poético en función de enriquecer el modo en que reinterpreta y modifica al mundo.

Hoy, todos aquellos que prefiguramos y producimos formas para el entorno humano ya sean estas arquitectónicas, graficas, objetuales o indumentales, nos ubicamos dentro de los roles de "proyectista" o diseñador", habitando un lugar específico dentro del territorio constructor de sentido por producción de saberes.

Este lugar específico llamado "proyecto" constituye, para Roberto Doberti (2016), una "cuarta posición", distinta a los enfoques adoptados para producir saberes por los tradicionales lugares del arte, la ciencia o la tecnología.

Para Doberti (2016) este deslinde es fundamental ya que entiende la imperiosa necesidad de asumir al proyecto como un lugar protagónico para la transformación y reinterpretación del mundo, ofreciendo un enfoque revolucionario que los lugares del arte, la ciencia y la tecnología no pueden brindar. Aquí no podemos extendernos en estos conceptos, solo nos interesa remarcar que nuestra "cuarta posición" en la producción de conocimientos de alcance universal es factible de concebirse gracias a los profundos cambios que la Bauhaus produjo en la conciencia global.

$\mathrm{Al}$ respecto advirtamos como ejemplo del impacto producido por la Bauhaus su mención, central o lateral, pero presente, en muy diversos textos sobre diseño o arquitectura. La lista es inabarcable, limitémonos a mencionar que Donis A. Dondis (1992) comienza su ya clásico texto La sintaxis de la imagen señalando el crucial aporte de la Bauhaus para resolver "la falsa dicotomía: Bellas artes y artes aplicadas", título ubicado en los inicios de su primer capítulo. En ese capítulo inicial Dondis reflexiona sobre los cambios históricos que nuestra cultura asigna a las ubicaciones de las diversas artes visuales sobre un eje en cuyos polos se oponen las bellas artes y las artes aplicadas.

$\mathrm{Al}$ respecto señala que en la mirada contemporánea se suceden sobre este eje, la pintura y la escultura como inmediatas a la noción de Bellas Artes, luego siguen los monumentos, la arquitectura, los oficios, la ilustración, la fotografía, el diseño gráfico y el diseño industrial, estas últimas, cercanas al polo de "artes aplicadas".

En su segundo gráfico Dondis muestra como estas ubicaciones cambian si evaluamos el contexto pre renacentista. Encontraremos allí claramente ubicada entre las Bellas Artes a la arquitectura, seguida de cerca por la escultura y, bastante más lejos, a la pintura, próxima a los oficios de ubicación inmediata entre las artes aplicadas.

Es en el tercer gráfico de Dondis donde se evalúa el enfoque de la Bauhaus. Allí, en el centro del extenso eje entre Bellas Artes y Artes aplicadas Dondis dice que la Bauhaus ubica en un solo punto todas las actividades dispuestas en un abanico: pintura, escultura, arquitectura, oficios, fotografía, diseño gráfico y diseño industrial. 
En su texto, por cierto, Dondis enfatiza que mucho antes que la Bauhaus, William Morris y los prerrafaelitas ya habían mostrado la misma tendencia conceptual, recordando a Ruskin diciendo: "El arte es uno y cualquier distinción entre Bellas Artes y Artes Aplicadas es destructiva y artificial" (Citado por Dondis, 1992, p. 17).

Hay consenso en señalar que el movimiento Arts and Crafts fue llevado al fracaso por su reaccionario concepto de que solo mediante la artesanía se podía producir arte, evitando el empleo de máquinas para la producción en serie. Walter Gropius no cometió este error, por el contrario, reinventó lo noción de artesanía y artesano al poner en valor el empleo de máquinas y producciones seriadas con el estricto objetivo de hacer llegar a la mayoría, por su bajo costo, productos de alta calidad visual. Este enfoque social está hoy tan naturalizado que es difícil encontrar diseñadores que a él se opongan. Aún en aquellos casos donde los contextos culturales abundan en artesanos herederos de saberes ancestrales, su empleo se efectúa desde responsables lógicas sociales y sustentables, impregnadas de la mirada ecológica contemporánea.

Y advirtamos en esta flexibilidad para resituar la mirada y determinar estrategias apropiadas a cada oportunidad y contexto otra deuda con la Bauhaus. Observemos asimismo que será precisamente desde nuestra flexible mirada como "proyectistas" dotados de un enfoque riguroso para la producción de formas como podremos renovar la noción de "arte". Un arte originado en procesos proyectuales y traducido en formas que trasciendan la función prosaica alcanzando la función poética. Este objetivo fundamental puede rastrearse en los múltiples escritos de los diversos profesores-artistas, quienes a veces coincidían en los modos de instrumentar pedagógicamente su logro, y muchas otras veces proponían, para satisfacer el mismo objetivo, caminos distintos.

Estas diferencias de "instrumentación pedagógica específica" que, paradójicamente perseguían alcanzar un núcleo de objetivos ideológicamente comunes, dificulta para los historiadores hablar de una única "pedagogía Bauhaus". Un rápido vistazo al modo en que actualmente se instrumenta el dictado de las asignaturas proyectuales por las muy diversas cátedras que coexisten en la misma universidad nos dirá que esta situación persiste hoy. ¿Es posible hablar de la existencia de un único modo pedagógico para la enseñanza del proyecto en la Universidad de Buenos Aires, por ejemplo?

Creemos que no es posible advirtiendo ya que ello no constituye, tal vez, un defecto, sino una virtud. La riqueza de ofertas pedagógicas que persiguen como objetivo común obtener un diseñador eficaz nos habla de la tan elogiada unidad en la diversidad. Ideal estético difícil de lograr.

Sobre estas diferencias en los enfoques pedagógicos, a veces sutiles y otros opuestos no podemos profundizar aquí. Los historiadores abundan en explicarlos. Sin embargo parece interesante referirnos a ellas desde el enfoque original de Claudio Guerri, especialista en semiótica y prestigioso profesor de morfología. Su mirada interesa precisamente para demostrar que la curiosidad por las lógicas de la pedagogía Bauhaus, exceden al ámbito tradicional de la historia.

Siendo Guerri especialista en Semiótica peirceana, encuentra que el célebre curso preliminar de la Bauhaus, dictado sucesivamente por tres maestros ilustres, constituye "una perfecta triada peirceana". Advirtamos que a Guerri (2007) le interesa explicar en su artículo en qué consiste una triada peirceana y porqué él ve en Itten, Moholy Nagy y Albers a los 
representantes de tres enfoques sobre la producción de forma que permiten conceptualizar los tres aspectos del signo según Peirce. Será oportuno recordar que la realidad que percibimos es una mera interpretación personal de un sistema de signos, y que cada signo para Peirce ofrece tres categorías interconectadas, nominadas como primeridad, segundidad y terceridad.

La primeridad, a la que luego Guerri (2014) en su Nonágono Semiótico llama "forma", alude a las condiciones abstractas o estructurales que el signo propone. En el caso del signo arquitectura la primeridad o "forma" consiste en los aspectos formales expresados en el proyecto. La segundidad a la que luego Guerri llama "existencia", alude a la manifestación existencial o material del signo. En el caso de la arquitectura el hecho construido es "segundidad" o "existencia". La terceridad, denominada ahora como "valor", alude a la relación entre el signo y el sujeto. El signo entendido como algo que sirve para alguien. En el caso de la arquitectura, el "valor" o "terceridad" consiste en su capacidad de ser habitable y satisfacer las prácticas sociales.

Desde este valioso esquema conceptual Guerri(2007) señala que Johannes Ittenen su propuesta pedagógica prioriza la terceridad o valor, ya que no concibe un arte incapaz de expresar emociones aun cuando intenta emplear leyes universales y entidades altamente abstractas en sus composiciones. Para Guerri la terceridad en Itten era la dominante mayor y la primeridad su acompañante menor, mientras que la segundidad existencial se manifestaba en los hechos concretos.

En el enfoque pedagógico de Lazlo Moholy-Nagy predominaba la segundidad o existencia, el hecho construido a partir de la lógica del material, de ser posible en serie y a bajo costo. Por ello los aspectos conceptuales o abstractos tenían un segundo lugar (primeridad o forma) mientras que el valor (terceridad) legitimaba el contexto de producción.

Para Joseph Albers, específicamente hacía el final de su periodo, lo esencial consistía en entender y operar con las leyes de agrupamiento y los atributos geométricos de las entidades compositivas, buscando estimular lo que Sven Hesselgren (1973) luego llamaría "experiencia estético formal”. Por ello, dice que Albers tiene como dominante mayor a la primeridad o forma, siendo entonces la dominante menor la segundidad o existencia, mientras que la terceridad, al igual que en Moholy-Nagy, servía como contexto de ejecución.

Reiteramos que este interesante análisis sobre los tres profesores-artistas del curso introductorio nos permitió profundizar en los diversos matices pedagógicos orientados hacía un objetivo común: la producción de formas estéticamente intencionadas mediante acciones racionales orientadas por saberes científicos y capacidades artesanales.

$\mathrm{Al}$ respecto y como esquema de lo dicho hasta aquí citaremos a Christian Norberg-Schulz (1999, p. 196): "La filosofía didáctica de la Bauhaus aspiraba a una nueva síntesis de arte y tecnología, esto es, a dar a los contenidos de la máquina un contenido real y significativo". Para alcanzar ese objetivo, la Bauhaus quería liberar simultáneamente la capacidad individual de "auto-expresión y desarrollar una estética objetiva, basada en el conocimiento científico”.

Conceptos parecidos enuncia Kenneth Frampton (1983) cuando señala que, luego de 1923, la orientación de la Bauhaus se hizo extremadamente "objetiva" merced a estar conceptualmente afiliada al movimiento "Neue Sachlickeit" (nueva objetividad). 
Diversos autores ubican por estas ideas a la Bauhaus dentro de la tradición y el espíritu de la Ilustración, explicando su singular éxito por su capacidad para expresar plenamente el espíritu de su época. Advirtamos que el "fenómeno Bauhaus" solo duró catorce años, desde 1919 a 1933, cuando los nazis, desde su lógica fascista, obviamente, la hicieron cerrar. Norberg-Schulz (1999, p. 196) señala que para entender cabalmente a la Bauhaus y a su producto secundario, la "arquitectura funcionalista", es necesario aprehender su concepto de libertad así como su ideal de orden: "Auto expresión no significaba satisfacción ni capricho personal, sino la capacidad para hacer uso creativo de los resultados de la investigación científica y del desarrollo tecnológico".

Esta actitud liberadora contribuyó a los dogmas del Movimiento Moderno, dogmas paradójicos que para "liberar" a la arquitectura de la tradición Beaux-Arts "prohibían" el uso explícito de sus saberes acumulados. En la postmodernidad, cuando se produce la feroz crítica a los resultados trivializantes del Movimiento Moderno, Paolo Portoghesi (1981) señala, con acierto, que la libertad de diseño dentro de las castrantes leyes compositivas de la modernidad impedía o dificultaba la aparición de formas nuevas que ya no estuvieran predeterminadas por el escueto lenguaje del irónicamente llamado "Estilo Internacional". Un dicho popular sostiene que el camino hacía el infierno esta pavimentado por buenas intenciones. Walter Gropius (1963) escribió, entre otros textos Alcances de una arquitectura integral, libro que en cierto período todos los estudiantes de arquitectura debían leer para "formarse". Allí se insistía, una y otra vez, en el riesgo de caer en algún"estilo" o "manierismo". La frase "el estilo es no tenerlo", usada por Gropius como intenso aforismo contra la tradición Beaux-Arts, fue usada por quien esto escribe, durante la postmodernidad como ironía... Ya que el desenfrenado eclecticismo de la ebriedad postmoderna convocaba al empleo aparentemente valido de cualquier "estilo" dentro de la producción de un mismo autor o estudio. De hecho, los muy sobrios e inteligentes Machado y Silvetti, con total coherencia y refinamiento intelectual, declaraban que su trabajo fundamental era "trabajar sobre los lenguajes y estilos", explorando cuales eran los más adecuados para cada contexto y programa. Rehuían con total conciencia y derecho al empleo del idiolecto obsoleto del Movimiento Moderno, buscando renovarlo. Lo consiguieron.

Lo paradojal en Gropius, como señalan Norberg-Schulz, Frampton y Wick, es que intentó denodadamente no construir un "estilo", pero sus edificios para el Bauhaus de Dessau se convirtieron en paradigmas del "estilo internacional”, según el irónico bautismo del perspicaz Philip Johnson.

Como señalamos al principio, nuestra deuda con la Bauhaus es enorme. Cambió una forma de ver al mundo y de enseñar a proyectar, pero como dice Goya: "El sueño de la razón engendra monstruos".

El funcionalismo arquitectónico, hijo legitimo del deseo por una objetividad que contribuyera a una producción artística menos caprichosa, degeneró en funcionalismo ingenuo, (Rossi, 1979) subsumiendo al arte de la arquitectura en las trivialidades de las prosaicas respuestas inmediatas que ofrecía la tecnología. La noción de belleza, también,fue trivializada y perseguida, a pesar de que todos los profesores de la Bauhaus era grandes artistas. Muchos de sus esfuerzos se malinterpretaron o pervirtieron (Pokropek-Cravino, 2019). Observemos, por ejemplo, que para Walter Gropius el concepto de "orden" debía aplicarse en la configuración de formas coherentes mediante leyes o principios generativos 
altamente flexibles, que podían y debían estimular la creación y variación de respuestas. Este enfoque se opone diametralmente a concebir la noción de "orden" como una actitud fascista que impone una única respuesta.

En un sentido similar, Gropius detestaba la noción de "estilo", por entender que recortaba las posibilidades creativas, y prefería afirmar que la pedagogía Bauhaus era portadora de un "método".

Siguiendo a Norberg Schulz (1999) y a Wick (1993) advirtamos que Gropius, siendo director y fundador de la Bauhaus, proponía lineamientos conceptuales generales pero evitaba el mismo tener materias a su cargo, expresando confianza en los profesores-artistas que había seleccionado, a los que daba sugerencias sin pretender coartar su libertad.

Insistimos asimismo en señalar que Gropius no veía contradicción alguna en que su propuesta pedagógica, basada en el rigor científico y la comunión con los tiempos de la máquina, centrada en los problemas de la arquitectura como madre de todas las artes y foco de todos los esfuerzos, fuera llevada a cabo por pintores geniales como Itten, Kandinsky, Klee, Muche, etc. Asumía que la componente subjetiva, intuitiva, irracional, propia de todo artista, era necesaria e inevitable para la producción de formas. Se trataba simplemente de evitar, para el diseño, un exceso de capricho que no se legitimara desde la propia lógica de la organización formal.

Observemos, en este mismo sentido, los arduos esfuerzos por construir conocimientos con rigor científico, aplicables al proyecto y producción de formas como leyes objetivas, que Klee, Kandinsky, Itten o Albers testimoniaron en su rica producción de textos. Todos estos artistas exitosos, enfrentados a la responsabilidad de enseñar su saber, debieron indagar en el mismo, explicitándolo y desarrollándolo mediante rigurosas investigaciones constructoras de nuevos saberes, para ellos y sus estudiantes. Una mirada personalizada a cada profesor-artista de la Bauhaus nos revela que, además de cumplir con sus funciones docentes, dedicaban un enorme tiempo y compromiso en la producción de textos y en el estudio de los nuevos conocimientos que su contexto producía.

Obras como Lo espiritual en el arte, y Punto y línea sobre el plano, de Vasily Kandinsky, aún hoy conmueven, aportándonos criterios y nociones para nuestra propia practica pedagógica y profesional.

Observemos, asimismo, que en una relativa simultaneidad histórica, mientras los profesores-artistas de la Bauhaus desarrollaban sus investigaciones traducidas a textos, los psicólogos de la Gestalt, básicamente el célebre grupo compuesto por Rubín, Köhler, Koffka y Wertheirmer, comenzaban o proseguían sus propias investigaciones sobre los mecanismos perceptuales que rigen la percepción y empleo de formas. Los significados intrínsecos a las distintas configuraciones formales, sostenidos por las lógicas de transformaciones propioceptivas y graficados en las ya célebres figuras "maluumna" y "takete", desarrolladas por Köhler y explicados por Arnheim (1997), Dondis (1992) y Hesselgren (1973), entre tantos otros, eran probablemente conocidas en la Bauhaus, aunque como advierte Wick (1993) Problemas de psicología recién se publicó en 1933 y Kandinsky no cita a Köhler ${ }^{1}$.

Es fácil sospechar, sin embargo, la existencia de vasos comunicantes entre individuos abocados apasionadamente a resolver los mismos problemas. Las coincidencias entre "malumna" y "takete" con los dibujos de Kandinsky para explicar el estímulo de emociones son absolutamente sorprendentes. Poco interesa aquí dilucidar quién fue el primero, o si 
fue un hallazgo simultáneo, cosa probable pues la historia produce numerosos ejemplos de situaciones similares, por ejemplo, el desarrollo coincidente de los sólidos de color de Pope y Johanson, quienes, cada uno por su lado, desarrollaron conceptos y dibujos casi idénticos.

¿Podemos hablar del "espíritu de la época" como productora de saberes coincidentes? La teoría de los "memes" de Richard Dawkins (2000) podría, tal vez aplicarse aquí.

En una breve digresión nos interesa señalar que el sólido de color de Pope, recién mencionado, fue empleado por César Janello (1977) en sus cursos de Morfología. Advirtamos entonces que los parecidos gráficos y conceptuales entre el sólido de Pope y el muy celebre paradigma mórfico de Janello, no son casuales (Guerri, 2012). Nos conmueve ver como la construcción de conocimiento original y valioso suele ser la reinterpretación, consciente o no, de aportes previos desarrollados para satisfacer objetivos distintos. Es esta capacidad de la mente la que posibilita emplear conceptos construidos en un universo disciplinar para ser empleados en otros, como por ejemplo, la semiótica aplicada al diseño. Advirtamos, por cierto, que Jannello (2007) llama a su artículo "Para una poética de la prefiguración" y plantea que todo acto de diseño debe entenderse como poético.

Volvamos ahora brevemente a los malentendidos y perversiones que padecemos por descontextualizar o reinterpretar dichos y hechos de la pedagogía Bauhaus.

Volviendo entonces a Gropius de la mano de Norberg-Schulz (1999), recordemos que en función del rechazo a la arquitectura Beaux-Arts, Gropius prefería definir al arquitecto como un "organizador" antes que como un "artista". La potencia estética de sus obras nos exime de más comentarios.

Algo parecido sucede con Hannes Meyer, sucesor de Gropius en 1928, cuando comienza, según Wick, la "fase de desintegración” (1928-1933).

Meyer tenía un enorme compromiso político con lo que todavía se denomina "izquierda". Su exacerbada preocupación social se traduce en el nivel del relato, en una actitud de ascetismo y sobriedad que intenta evitar toda "frivolidad" o "gesto superfluo", lo que lo lleva erróneamente a creer que debe "evitar todo esteticismo".

Los historiadores sospechan que si Walter Gropius lo eligió como sucesor no fue por sus dichos, opuestos al compromiso artístico que Gropius sí expresaba, sino por sus hechos: Meyer era un arquitecto maravilloso cuyas obras exudaban una sobria belleza. Como suele suceder pueden existir notables diferencias entre "lo escrito y lo construido". Arquitectos que se autoperciben como intensamente democráticos producen a veces obras cuya expresión formal es, a todas luces, fascista. Este no es el lugar para extender los argumentos sobre dicho fenómeno. Interesa solamente echar luz sobre lo actuado por Meyer y más tarde por Mies van der Rohe.

Revisemos sus dichos en "Bauhaus y Sociedad": "Construir y crear son una misma cosa, y constituyen un acontecimiento social. En cuanto colegio mayor de la creación la Bauhaus no es un fenómeno artístico, pero si social" (Citado por Wick, 1993, p. 48).

Más adelante dice Meyer: "Nuestra labor es servir al pueblo, nosotros no buscamos ni un estilo Bauhaus ni una moda Bauhaus", y hacía el final, para "aclarar" algo más sus conceptos, manifiesta: 
Actualmente nosotros buscamos por medio del arte exclusivamente la cognición de un nuevo orden objetivo, destinado para todos, manifestación y medio hacía una sociedad colectiva. La nueva enseñanza de la arquitectura es una enseñanza del conocimiento de la existencia. En cuanto, enseñanza de creación constituye la más alta canción a la armonía. Como enseñanza social, es una estrategia de compromiso de las fuerzas cooperativas y de las fuerzas individuales dentro de la convivencia de un pueblo (Citado por Wick, 1993, p. 48).

Las frases señaladas con negrita muestran que Meyer seguía percibiéndose como un tipo particular de "artista", y que su misión era servir al pueblo ofreciéndole formas industrializadas y a bajo costo pero "cargadas de armonía" como resultado de un aprendizaje que estimulaba la constante innovación obtenida al entrenar un espíritu creativo que rechazaba lo tradicional por ya sabido.

La ambivalente actitud de Hannes Meyer en relación a la noción de "arte”, ya sea "puro" o "aplicado" como algo, por momentos, frívolo o secundario, llevó a una redefinición completa sobre la pedagogía Bauhaus, especialmente en lo que hacía a la enseñanza de la arquitectura que, ahora adquiriría un enorme protagonismo, aunque se focalizara en su compromiso social.

Nos parece oportuno citar aquí los comentarios de Rainer Wyck sobre las proclamas de Meyer:

En estas frases programáticas se ve claramente que bajo la dirección de Meyer la Bauhaus se ha despedido definitivamente de la idea de escuela de arte y que la idea de unos talleres de producción se inclinó absolutamente hacía la satisfacción de necesidades sociales. La sección de arquitectura pasó a ser el punto central de la Bauhaus, pero no en el sentido integral apuntado en el manifiesto fundacional, sino como departamento especial en gran parte autónomo de los demás departamentos (a excepción del taller de terminado). Con ello se produjo un nuevo debilitamiento de la influencia de los pintores y por consiguiente una merma de la calidad espiritual de la Bauhaus (Wick, 1993, p. 48-9).

Señalaremos que Schlemmer y Klee, entre otros, renunciaron por el disgusto que Meyer les causaba. Kandinsky prosiguió pero en su rol de gran adversario.

Coincidimos con Wick en su lectura sobre el debilitamiento de la "calidad espiritual" de una pedagogía proyectual obsesionada por la resolución de problemas técnicos o sociales y que en nombre de la urgencia por resolverlos, posterga o elimina el consciente incremento de la dimensión poética que sus productos deben ofrecer.

Otra vez lo urgente nubla lo importante. Observemos que al focalizarse en la enseñanza de la arquitectura en desmedro de la otras "artes aplicadas" también se produce una pérdida de la conciencia global sobre la relación profunda entre todos los productos del diseño. Esta mutilación y fragmentación en la enseñanza del diseño, deslindándolo en áreas específicas, produce un trauma conceptual cuyas heridas solo se justificarían si con el correr de los años pudiera verificarse que cada "fragmento", gracias a su autonomía relativa, ha 
podido profundizar en la construcción de conocimientos específicos, propios de su sector disciplinar.

Ese parece haber sido el enfoque que llevó oportunamente, en varios países, a fragmentar la carrera de arquitectura en las diversas áreas del diseño. Quien esto escribe inició sus estudios de arquitectura en un período en el que la misión del arquitecto consistía en saber producir desde ceniceros hasta ciudades. En los términos de una vida es para nosotros muy reciente el deslinde en carreras autónomas para el diseño industrial, grafico, indumental o de imagen y sonido.

No es casual que los primeros cuerpos de profesores en esas carreras hayan sido exclusivamente arquitectos. Tampoco era pedagógicamente imposible ya que todos los diseñadores tenemos en común el haber adquirido un saber hacer poético y universal para la producción de formas, más allá de cuales sean las necesidades simbólico-operativas que esas formas deben cumplir. Ese saber hacer poético y universal, generador de formas coherentes y estéticamente intencionadas, tiene en algunos países, dentro de la currícula de cada carrera, asignaturas específicas destinadas precisamente a construir esa base general para todo acto proyectual. En Argentina y otros países latinoamericanos esas asignaturas se nominan "Morfología", haciendo referencia a lo que entendemos por una disciplina con rigor científico y orientación poética. Disciplina destinada a reunir y producir conocimientos sobre la conceptualización y producción de formas, así como los modos en que estas formas estimulan en sus usuarios significados, conductas y emociones, determinantes de experiencias estéticas para la satisfacción plena de prácticas sociales.

Obvio es advertir que el territorio de estudios en "Morfología" coincide con la mayoría de las investigaciones y propuestas pedagógicas iniciadas en la Bauhaus. Profundizaremos en esta relación más adelante, ahora y con ánimo de completar o, al menos, ampliar nuestra lectura sobre algunos malentendidos de la pedagogía Bauhaus que siguen causando conflictos al momento de conceptualizar los objetivos fundamentales de una pedagogía para el diseño, revisaremos algunos dichos y actitudes de Mies Van der Rohe.

El tercer director de la Bauhaus había inicialmente rehusado ser sucesor de Gropius, pero luego diversas razones lo llevaran a tomar el lugar de Hannes Meyer, desplazado por motivos políticos. Recordemos que Wick establecetres períodos para la Bauhaus: creación, consolidación y desintegración en relación a los directores de la institución. Mies, con Meyer, se ubica en este último triste periodo.

En el momento de asumir el cargo en 1930, Mies van der Rohe ya era conocido como un arquitecto exquisito. Recordemos que su pabellón de Barcelona era de 1929. Bajo su dirección se enfatizó la enseñanza protagónica de la arquitectura en desmedro de las otras "artes aplicadas". A diferencia de Meyer a Mies le importaba incrementar la calidad de la forma arquitectónica como objetivo primordial de su enseñanza, desplazando así el foco puesto sobre el compromiso social, sin por ello negarlo, y determinando además el carácter periférico de los "otros" diseños.

Esta actitud de Mies poniendo énfasis en la renovación de la arquitectura mediante sus profundos estudios sobre nuevas lógicas de composición espacial y su relación con las tecnologías y materiales de avanzada ${ }^{2}$, evitando así trivializar la producción arquitectónica al subsumirla en meros respuestas sociales o técnicas, se contradice si leemos algunos escritos fuera del contexto que les da sentido. 
Kenneth Frampton (1987) nos trae a Mies diciendo: "Nos negamos a reconocer problemas de forma; solo hay problemas de construcción. La forma no es el objetivo de nuestro trabajo sino solo el resultado. La forma por sí misma, no existe".

Y en otro lugar dice Mies: "Espero que nadie crea que esto de la arquitectura tenga nada que ver con la composición, por el contrario, solo tiene que ver con la construcción" (Citado por Miranda, 2011).

Estas frases decididamente encaminadas a revalorizar las lógicas de generación formal mediante su coherente adecuación a las lógicas del material y de la técnica, buscando establecer así un saber hacer poético basado en la idea de "techne" pero trascendiéndola en "poiesis" constructiva,buscan evitar, como en el caso de Walter Gropius, caer en los "formalismos" caprichosos del Beaux-Art.

Observemos asimismo que otros autores, como Cravino (2020) y Aleman (2020) señalan la enorme influencia que sobre la Bauhaus ejercieron los conceptos formulados por el grupo de intelectuales conocido como "Circulo de Viena", quienes entendían al "formalismo" y a la "metafísica" como enemigos comunes.

En otro escrito ya hemos señalado que Mies, luego de su iniciático viaje a Estados Unidos, donde tomó contacto con otros enfoques sobre la relación entre arte, diseño y arquitectura dijo: "Los arquitectos son artistas". Y mantuvo esta mirada hasta su muerte.

Es para nosotros obvio que aquel arquitecto exquisito, amigo y admirador de Paul Klee, desmiente con su obra toda duda sobre la condición poética de la forma arquitectónica y su capacidad para estimular la experiencia estética ${ }^{3}$.

Nos subleva entonces que aún existan arquitectos o diseñadores que tiendan a trivializar la producción de forma subsumiéndola en sus aspectos técnico-constructivos.

Para nosotros Mies contribuyó enormemente a la noción de arquitectura como arte más allá de algunos dichos desafortunados y de que la crítica contemporánea lo señale como cómplice de los nazis, traidor de sus amigos, esposa, hijas y amantes; bebedor empedernido, narcisista y pedante. Un mal tipo en definitiva. Advirtamos que los grandes artistas y pensadores son seres complejos. Eso no los perdona pero los explica. Heidegger es otro gigante de la filosofía cuyas conductas éticas fueron repugnantes.

\section{Bauhaus - Arquitectura - Diseño - Morfología - Heurística. Principios para una proyectualidad poética}

Nos interesa ahora establecer brevemente una plataforma conceptual que nos permita operar en la esquematización de algunos principios para una proyectualidad poética.

Ya hemos establecido previamente que por proyectualidad poética podemos entender un conjunto de acciones de prefiguración formal tendientes a una producción de formas que reinterpretan y renuevan al mundo; siendo esta actitud innovativa el rasgo protagónico de un accionar poético. También dijimos que la noción de poética abarca asimismo al estudio de las lógicas de organización de los signos para estimular una experiencia estética. 
Desde esos enfoques nuestra preocupación es encontrar lógicas de organización de la forma tendientes a vehiculizar un mensaje estético cuya interpretación constituya una revelación poética, es decir, un incremento del mundo.

Hemos señalado asimismo que estas tareas de investigación para construir conocimientos sobre los problemas inherentes a la generación y evaluación de formas se dan dentro de ciertas disciplinas como la Morfología o la Heurística, en las que concurren múltiples saberes interdisciplinares, como la Semiótica, la Psicología, la Etología, la Antropología, etc. Aquí y ahora pretendemos simplemente insistir en la relación entre estas problemáticas y áreas disciplinares con las experiencias pedagógicas que la Bauhaus desarrolló en sus catorce años de existencia.

Insistamos en señalar que quien esto escribe es desde hace años profesor de Morfología y posee una maestría en "Lógica y técnica de la forma". Será desde esa mirada que podemos entender a la Bauhaus básicamente como un curso complejo de Morfología, ya que los temas y problemas que sus profesores artistas investigan y desarrollan está en el origen mismo de nuestra disciplina. Asimismo la Heurística, entendida como la disciplina focalizada en indagar sobre los modos de inventar, hermana de la Morfología, también encuentra en la Bauhaus los primeros intentos sistemáticos para establecer los mecanismos mentales de la creación humana. Entre ellos, como destaca Gastón Breyer (2000), se encuentra la Geometría entendida como una gramática del diseño y tratada con renovadora mirada por Moholy Nagy, Vantongerloo, Max Bill, Kandinsky y Klee. Al respecto Breyer (2000, p. 19) dice: "Son nuevas gramáticas del buen diseño, con nuevos enfoques, otros horizontales, nuevas didácticas, pero el mismo espíritu de racionalidad, estética y poesía”.

Aprovechamos esta cita para reforzar, con otra, la relación conceptual entre proyecto, geometría y poesía. Breyer (20000, p. 20) dice: "Una poesía es un texto alquímicamente purificado y sublimado por la geometría de lo esencial; una geometría es el poema subyacente a la forma material cuando toda impureza ha pasado por el alambique del espíritu".

Conviene recordar aquí que fue Gastón Breyer quien en la Universidad de Buenos Aires en el año 1955 organizó junto a Lepera las primeras cátedras dedicadas específicamente al estudio de la generación de formas, que por aquel entonces se llamaron "Visión", después "Sistemas visuales" y ahora "Morfología" (Devalle, 2009). Debemos también a Breyer la creación del laboratorio de Heurística, actualmente dirigido por Dora Giordano (2009), autora de Cuestiones de Diseño.

Observemos ahora que tanto en esas primeras cátedras como en las actuales la estrategia pedagógica consistía en prefigurar y producir formas a partir de consignas que no podían admitir un resultado único, aunque si debía ser coherente con variables enunciadas tanto por los profesores como por los estudiantes.

A estos resultados se llegaba por el clásico proceso proyectual iterativo basado en lo que pedagogos como Donald Schon (1998) llaman, entre maravillados y sorprendidos, "procesos de reflexión en la acción”. Procesos mentales que, por cierto, todo diseñador o artista conoce: La forma nace mientras se hace, el diseñador es padre, madre y partera.

En estos procesos intervienen grandes dosis de racionalidad, pero también mucha intuición, entendida hoy como "abducciones hipocodificadas". Dichas "abducciones" producen respuestas coherentes pero eluden explicitar los complejos procesos mentales que las 
generaron. Es obvio señalar que estas estrategias pedagógicas eran las protagónicas en los cursos introductorios de Itten, Moholy Nagy y Albers.

No tan obvio es recordar que en los escritos de estos profesores-artistas se insistía en estimular los procesos creativos del estudiante dejándolo en "libertad" de encontrar respuestas de manera autónoma, sin estarle "encima" dándole información o consejos que pudieran limitar la originalidad y valor de sus productos.

Sonreímos cuando algunos docentes recomiendan leer El maestro ignorante de Jacques Ranciere (2003), quien propone adoptar una relación "horizontal" con el estudiante para no "inhibirlo", actitud eficaz que Itten puso por escrito hace cien años, siendo seguido por el resto de los maestros de la Bauhaus.

Muchos profesores en la actualidad o en un pasado mediato han desarrollado estrategias pedagógicas con objetivos y productos muy similares a los desarrollados por la Bauhaus. Algunos desde una actitud consciente de reelaboración y actualización de ideas y estrategias eficaces y probadas, otros por la mera repetición de gestos pedagógicos aprendidos acríticamente, naturalizados como obvios y necesarios. Se enseña "así” porque "siempre se enseñó así". Funciona. "Si no está roto, no lo arregles" o "lo bueno es enemigo de lo mejor" son aforismos muy aplicables a estas actitudes que tienden a la esclerosis.

Por cierto, es muy difícil proponer estrategias renovadoras que no tengan algún antecedente más o menos evidente en los procesos y productos de la Bauhaus.

Como ejemplo de lo dicho y como homenaje a Gastón Breyer recordaremos aquí algunos conceptos suyos vertidos en un célebre reportaje que el diario Tiempo Argentino le hizo en 1985. Allí Breyer explicaba al “objeto épsilon”, instrumento pedagógico que marcó a fuego a generaciones de profesores y estudiantes. Nosotros incluidos.

Lo llamamos Épsilon porque nosotros en la cátedra hicimos una clasificación de todos los objetos. Los objetos que forman el primer grupo son los que sirven para algo, los que tienen una utilidad práctica como por ejemplo una tenaza, son los objetos que nosotros llamamos Alfa. Después los objetos Gamma son los de función estética, los de intención estética, es decir los objetos de arte. Después los objetos habitables los llamamos objetos Beta. Después vienen los objetos Delta, que tienen función comunicativa, los mensajes. Y los Épsilon son los objetos que no tienen ninguna utilidad; los definimos como negativa. Es un objeto que no sirve para nada; es un objeto que no tiene fin estético, no tiene preocupación por ser estético; aunque claro, es mejor si sale lindo. No es un objeto que remite a un mensaje, es decir, que no dice nada (Breyer, 1985a, p. 2).

Sobre esta explicación de la taxonomía objetual y los modos pedagógicos de encarar la producción de estos objetos por parte de los estudiantes, el periodista, bastante informado, pregunta no sin cierta picardía: “¿En la Bauhaus no se trabajó con este tipo de cosas?” A lo que Breyer responde secamente: "No, era distinto, además hace cincuenta años. Está, sí, dentro del espíritu de la Bauhaus" (Breyer, 1985a, p. 3).

Las últimas frases demuestran la indudable honestidad intelectual de Breyer quien, a regañadientes, no puede evitar reconocer influencias decisivas. Por cierto, observemos que 
en sus escritos reconoce a la Bauhaus en múltiples oportunidades como el inicio moderno sobre la investigación de la forma.

Mencionemos ya que las operatorias para producir objetos similares al Épsilon fueron infinitamente reelaboradas por numerosos profesores que olvidaron citar a Breyer. Y poco conocen de lo actuado en la Bauhaus.

Parece por cierto oportuno mencionar que, desde nuestra Semiótica actual aplicada a la Morfología, la taxonomía objetual de Breyer, tal como la explicó, puede ser hoy severamente atacada.

La pretensión de "inutilidad" del objeto Épsilon, su indiferencia a factores estéticos (aunque es mejor que salga lindo) y la supuesta incapacidad para expresar mensajes es, a todas luces, absurda. No existe ningún objeto de la realidad que hoy pueda rigurosamente clasificarse dentro de la taxonomía de Breyer sin obviar gran parte de su capacidad expresiva. Recordemos que todos los objetos son pasibles de ser leídos desde cinco enfoques básicos:

- El aspecto sintáctico-morfológico que muestra la relación de coherencia entre las partes y el todo luego de un análisis formal.

- El aspecto operativo que denota el uso posible que el humano asigna a la forma, en última instancia, proyectil, pisa papeles o proyector de sombra.

- El aspecto funcional que denota el uso dentro de un código social que posibilita su empleo, dirigido, como el operativo, a satisfacer necesidades prosaicas o utilitarias.

- El aspecto simbólico-metafórico abierto, intrínseco a la forma, que expresa por asociación significados abstractos (hostil, amable, etc.) del tipo "malumna" y "takete", orientado a satisfacer la dimensión poética humana.

- El aspecto simbólico-metafórico cerrado, o convencional portador de mensajes connotados inscriptos en signos socializados pero devaluables, también dirigido a necesidades espirituales (Pokropek, 2015a)(Pokropek, 2015b).

Diseñando en la forma el porcentaje protagónico expresivo de cada aspecto es posible enfatizar o minimizar el estímulo comunicativo de tres mensajes básicos: el estético, el kitsch y el literal.

Aquí no podemos extendernos en estos temas, que también son deudores de las investigaciones iniciadas en la Bauhaus.

No obstante debemos insistir en señalar el enorme aporte que Breyer hizo al proponer la producción pedagógica de "objetos Épsilon” pues en su lógica de prefiguración-producción se hallaban los mecanismos para estimular la generación creativa de formas desde un alto nivel de abstracción, solo posible al no inhibirlo por consignas previas operativas, estéticas o simbólicas. La única consigna intensa era que el objeto debía tener materialidad y "transformarse" mediante la aplicación de alguna fuerza sobre su lógica estructural.

El resultado era un artefacto cuyos grados de complejidad dependía de las capacidades e intenciones de cada estudiante. Este artefacto debía evidenciar el modo en que "operaba" para "transformarse", lo cual implicaba concebir partes fijas y móviles, distintos colores y texturas, etc.

Es obvio que dicho "artefacto" en su mecánica expresión tiende a estimular el mismo tipo de experiencia estética que las máquinas ofrecen desde su aparente perfección. Ello es in- 
evitable dado el alto grado de autorreferencialidad formal que el épsilon no podía ni debía evitar. En el mismo sentido operaba el artista Jean Tinguely (1925-1991) genial creador de máquinas inútiles. Gastón Breyer, por su enorme erudición, sabía perfectamente que el diseño y producción de sus "objetos inútiles" se traducía en profundos aprendizajes sobre el modo poético de generar formas. Su tramposo y aparentemente liviano discurso a la prensa contrasta fuertemente con el rigor y profundidad de sus escritos. Este contraste también es una propuesta pedagógica.

\section{Despedidas para un retorno}

Nuestro artículo ya es excesivamente extenso, con ánimo de construir un cierre lógico nos proponemos ahora ofrecer una apretada síntesis de lo ya dicho y lo por decir.

A cien años de su inauguración los temas y problemas que la Bauhaus instaló en el debate internacional para configurar lógicas pedagógicas para una proyectualidad poética siguen vigentes y exigen constantes actualizaciones y profundizaciones. Nuestros planes de estudio deben incorporar las nuevas tecnologías digitales como en su momento, la Bauhaus vio en la industria el modo de renovar al mundo. La globalización debe ser virtud y no defecto.

Temas esenciales como el manejo del color, la textura, el material, la geometría, el ritmo, la articulación de partes, la tensión dialéctica de opuestos, la autorreferencialidad y coherencia de forma, los modos de expresar y estimular significados, emociones y conductas, siguen siendo prioritarias para una pedagogía orientada a construir seres libres y creativos, capaces de reinterpretar, renovar y transformar al mundo, haciéndolo más solidario y bello.

El compromiso de aquellos profesores-artistas al brindarse con rigor y entusiasmo a la tarea docente, quitando tiempo existencial a su praxis profesional para invertirlo en la generación de textos constructores de saberes nuevos debe ser imitado. Por respeto a esos esfuerzos debemos conocer y reinventar aquellos saberes que hoy aún presentan flaquezas o indeterminaciones nocivas por paralizantes. No se trata de reconocer y esclerosar los conocimientos construidos en aras de un mal entendido homenaje; por el contrario, se trata de reconocerlos para incrementarlos o desecharlos, según sirvan como andamios o jaulas. Es necesario entender al proyecto como un territorio para transformar al arte, y entender al arte como el espacio pleno para renovar al ser. La Bauhaus nos ha dejado una herencia enorme. No la despilfarremos.

Gracias.

\section{Notas}

1. Tal vez los estudios sobre la percepción de la Gestalt llegarían al Bauhaus intermediados por algunos miembros del Círculo de Viena, preocupados por estas cuestiones... 
2. A partir de esta experiencia docente podemos suponer, empezó Mies a explorar sobre sus famosas casas con patio (Abalos, 2000).

3. Decía al respecto Enrique Browne (1998): "No se puede culpar a Mies si generaciones de arquitectos tuvieron una visión minimalista de la arquitectura, pero sin su poesía..."

\section{Bibliografía}

Abalos, I. (2000). La buena vida. Barcelona: Gustavo Gili.

Arnheim, R. (1997). Arte y percepción visual. Buenos Aires: EUDEBA.

Breyer, G.; Doberti, R. y Pando, H. (2000). Bases Conceptuales del Diseño. Buenos Aires: Ediciones de la Facultad de Arquitectura, Diseño y Urbanismo, Universidad de Buenos Aires.

Breyer, G. (1978). "La heurística del diseño, entre el teorema y el poema" en Revista Summa No 131, diciembre de 1978.

Breyer, G. (1985a). "La arquitectura del pensamiento" en Tiempo Argentino Cultura, 11 de agosto de 1985

Breyer, G. (1985b). "La investigación de los problemas estéticos" en Tiempo Argentino Cultura, 11 de agosto de 1985.

Browne, E. (1998). "Arquitectura moderna y decoración” en Summa + N³2, agostoseptiembre 1998.

Dawkins,R.(2000). El gen egoísta. Barcelona: Editorial Salvat.

Devalle, V. (2009). La travesía de la forma. Emergencia y consolidación del Diseño. Buenos Aires: Paidós.

Doberti, R. (2006). Espacialidades, Infinito, Buenos Aires

Doberti, R. (2016). "La Tesis en la Posición del Proyecto" en Zicovich Wilson, Sergio (comp.) (2016). La Tesis de Posgrado en arquitectura, Diseño y Urbanismo. Buenos Aires: NOBUKO/ Diseño Editorial -FADU-UBA.

Dondis, D. A. (1992). La sintaxis de la imagen. Introducción al Alfabeto visual. Barcelona: Editorial Gustavo Gili.

Eco, U. (1986). La estructura ausente. Introducción a la semiótica. Barcelona: Lumen.

Frampton, K. (1983). Historia crítica de la Arquitectura moderna. Barcelona: Gustavo Gili.

Frampton, K. (1987). "Modernidad y tradición en la obra de Mies van der Rohe" en Mies Van der Rohe cumple 101, Colección Summarios No 114, Buenos Aires, 1987.

Giordano, D. (2009). Cuestiones de Diseño. Buenos Aires: Nobuko.

Gropius, W. (1963). Alcances de una Arquitectura Integral. Buenos Aires: La Isla.

Guerri, C. y Acebal, M., comps. (2014). Nonágono Semiótico. Un modelo operativo para la investigación cualitativa. Buenos Aires: Eudeba.

Guerri, C. (2012). Lenguaje Gráfico TDE. Más allá de la perspectiva. Buenos Aires: EUDEBA.

Guerri, C. y Huff, W. (2007). “Tres maestros del curso preliminar de diseño en la Bauhaus” En De Signis Estética y semiótica: bordes de la representación: Publicación de la Federación Latinoamericana de Semiótica (FELS) No. 11, 2007, pp. 185-19.

Heidegger, M. (1994). "Poéticamente habita el hombre". Conferencias y artículos. Barcelona: Serbal. 
Heidegger, M. (2006). Arte y Poesía. México: Fondo de Cultura Económica. Hesselgren, S. (1973). El Lenguaje de la Arquitectura. Buenos Aires: Eudeba. Norberg Schulz, C. (1999). Arquitectura Occidental. Barcelona: Gustavo Gili. Jakobson, R. (1975). Ensayos de lingüística general. Barcelona: Seix Barral. Jannello, C. (1977). “Para una poética de la prefiguración” en Summarios No 9/10 Morfología, Buenos Aires: Ediciones Summa, pp. 24-28.

Miranda, A. (2011). “El alma del arquitecto: conferència inaugural del curs 2010-2011”. En Visions No 9, p. 130-143.

Pokropek, J. y Cravino, A. (2019). “La recuperación de la noción de belleza en el campo de la Arquitectura y el Diseño" ponencia presentada en XXXIII Jornadas de Investigación XV Encuentro Regional, FADU-UBA.

Pokropek, J. (2015a). La EspacialidadArquitectónica. Introducción a sus lógicas proyectuales para una morfología de las promenades. Buenos Aires: Nobuko.

Pokropek, J. (2015b). “Diseño, Arquitectura y Arte”. Ponencia presentada en el Sexto Congreso Latinoamericano de Enseñanza del Diseño, Universidad de Palermo, julio 2015.

Portoghesi, P. (1981). Después de la arquitectura moderna, Colección Punto y Línea. Barcelona: Gustavo Gili.

Ranciere, J. (2003). El maestro ignorante. Barcelona: Laertes.

Rossi, A. (1979). La arquitectura de la ciudad. Barcelona: Gustavo Gili.

Schon, D. (1998). La formación de Profesionales reflexivos. Madrid: Paidós.

Wick, R. (1993). La pedagogía de la Bauhaus. Barcelona: Alianza Forma.

\begin{abstract}
The influence of the Bauhaus school on the current ways of implementing pedagogical logics aimed at the training of architects and designers has been enormous. Both its undeniable contributions in the construction of knowledge and in the configuration of criteria and methods was so deep, that it has been "naturalized", sometimes forgetting the origin and context which determined it. It is interesting to evaluate, as teachers in the project areas, what knowledge, criteria and methods are still in force and applicable to the instrumentation of effective pedagogical logics for a poetic projectuality. It is also interesting to figure out how the procedures and theories developed by the Bauhaus constitute the very origin of current Morphology and Heuristics disciplines.
\end{abstract}

Keywords: Bauhaus - design - morphology - heuristics - poetics.

Resumo: A influência da Bauhaus nas atuais formas de implementar lógicas pedagógicas voltadas para o treinamento de arquitetos e designers tem sido enorme. Suas inegáveis contribuições na construção do conhecimento e na configuração de critérios e métodos foram tão profundas que foram "naturalizadas", às vezes esquecendo a origem e o contexto que o determinaram. Aqui é interessante avaliar, como professores nas áreas do projeto, quais conhecimentos, critérios e métodos ainda estão em vigor e aplicáveis à instrumentação de lógicas pedagógicas eficazes para uma projetualidade poética. Também é interes- 
sante observar como os procedimentos e teorias desenvolvidos pela Bauhaus constituem a própria origem das atuais disciplinas de Morfologia e Heurística.

Palavras-chave: Bauhaus - design - morfologia - heurística - poético.

[Las traducciones de los abstracts fueron supervisadas por el autor de cada artículo] 